\title{
Evaluation of biophysical skin parameters and assessment of hair growth in patients with acne treated with isotretinoin
}

\author{
Małgorzata L Kmieć, Anna Pajor, Grażyna Broniarczyk-Dyła \\ Department of General, Esthetic Dermatology and Dermatosurgery, Medical University of Lodz, Poland
} Head: Prof. Grażyna Broniarczyk-Dyła MD, PhD

Postep Derm Alergol 2013; XXX, 6: 343-349 DOI: $10.5114 /$ pdia.2013.39432

\begin{abstract}
Introduction: Treatment of the severe forms of acne vulgaris remains a challenge. Isotretinoin is a drug often used in these cases. Retinoids affect the mechanisms that play a role in the pathogenesis of acne, reduce the production of sebum and sizes of the sebaceous glands. However, isotretinoin appears to have undesirable side effects in the skin, mucous membranes and hair.

Aim: The aim of this study was to assess the effect of acne vulgaris treatment with isotretinoin on biophysical skin parameters: skin sebum and stratum corneum hydration levels, transepidermal water loss values, $\mathrm{pH}$, erythema and hair growth parameters: total number, density and proportion of anagen hair.

Material and methods: The study included thirty patients with acne types: papulopustular, conglobata and phlegmonosa. Patients were treated with isotretinoin at a dose of $0.5-1.0 \mathrm{mg} / \mathrm{kg} /$ day for a period of $4-7$ months. The measurements of skin biophysical parameters were performed before and after the treatment using Sebumeter SM815, Corneometer CM825, Tewameter TM300, MX Mexameter MX18 and Skin-pH-Meter PH908. Hair growth parameters were evaluated with FotoFinder Dermoscope using the TrichoScan Professional V3.0.8.76 software. Results: The results of biophysical skin parameter measurements after the treatment showed a reduction in the severity of seborrhea. However, the skin was dry, which confirmed a lowered degree of stratum corneum hydration and an increase in transepidermal water loss values. Moreover, severity of erythema, an increase in $\mathrm{pH}$ value, and variations in selected hair growth parameters: decrease in total count, density and proportion of anagen hair were demonstrated.

Conclusions: The reduction in the skin sebum levels was observed after the treatment. There was dryness of the skin, which was confirmed by biophysical skin parameter measurements. Changes in the hair growth parameters showed telogen effluvium hair loss.
\end{abstract}

Key words: acne vulgaris, isotretinoin, biophysical skin parameters, trichoscan.

\section{Introduction}

Acne vulgaris is an inflammatory skin disease, usually occurring at the age of 11 and 30 years [1, 2]. Skin lesions characteristic of acne are blackheads as well as inflammatory changes such as papules, pustules and cysts, which result in post-inflammatory hyperpigmentation and scarring. Changes are usually present on the facial skin and upper parts of the body. Disease pathogenesis includes a number of factors. These are excessive production of sebum by the sebaceous glands, the innate tendency to hyperkeratosis of hair follicles; also bacterial flora (Propionibacterium acnes, Staphylococcus epidermidis) and fungus Pityrosporum ovale are involved $[3,4]$. The activity of the pilosebaceous unit depends on the receptor stimulation by androgenic hormones. They stimulate the production of the abnormal composition of sebum and affect the sebaceous gland hypertrophy. Excessive sebum production is closely linked to the severity of acne [5,6]. Chronicity of the disease and changes that are frequently localized on the facial skin affect the mental state of patients, resulting in decreased quality of life [7].

Address for correspondence: Prof. Grażyna Broniarczyk-Dyła MD, PhD, Department of General, Esthetic Dermatology and Dermatosurgery, Medical University of Lodz, Pl. Hallera 1 building 6, 90-647 Lodz, Poland, phone: +48 4263930 93, fax: +48 4263930 94, e-mail: grazyna.broniarczyk-dyla@umed.lodz.pl

Received: 11.01.2013, Accepted: 20.08.2013. 
In the 1970s, oral isotretinoin was used in the therapy of acne. It was a breakthrough in its treatment. The indications for the systemic administration of retinoids are severe forms of acne and varieties which do not react to other treatment methods or those associated with psychological problems (psychological scarring) [8].

Retinoid treatment gives good results, affects most mechanisms playing a role in the pathogenesis of acne, i.e. reduces sebum production and the sebaceous gland size as well as inhibits the microcomedone formation limiting the possibility of $P$. acnes development $[9,10]$.

However during treatment, isotretinoin induces undesirable side effects in the skin such as dryness, redness, increased propensity to injuries, inflammatory changes within the mucous membranes and their dryness, hair loss and thinning, joint and muscle pain, and additional abnormalities, such as: elevated levels of transaminases, bilirubin, alkaline phosphatase, triglyceride, cholesterol, erythrocyte sedimentation rate and changes in blood cell count $[11,12]$. The occurrence of these adverse reactions clearly indicates the desirability of selecting the appropriate dosage of the drug and time of application. The treatment should be individualized. The most commonly used dose of isotretinoin is $0.5-1.0 \mathrm{mg} / \mathrm{kg} / \mathrm{day}$, while a lower dose is administered for the first month to evaluate drug tolerance. Isotretinoin is administered in two divided doses, after a meal, because of its lipophilic nature. The treatment period lasts from 4 to 7 months; the total drug intake is 120-150 mg/kg of body weight. An exceeded drug dose has no influence on the increase in the treatment effect [13]. The drug is registered for the therapy of patients over 12 years of age. At least 10\% of patients have relapse after therapy especially in the case of total dose application less than $120 \mathrm{mg} / \mathrm{kg}$ [14]. Retinoids have a teratogenic effect, may cause fetal malformations, such as central nervous system disorders, abnormalities of the external ear, cardiovascular defects, facial dysmorphism, microphthalmia, thymus, parathyroid and skeletal abnormalities and also decrease in IQ [15]. Because of the possibility of these complications, isotretinoin treatment of women in childbearing age requires taking contraceptives. The inclusion of drug requires the exclusion of pregnancy (a pregnancy test required) and contraceptives should be administered one month before initiating the treatment and continued for 1-2 months after the end of therapy [16, 17].

Isotretinoin should be used with caution in patients with a history of psychiatric disorders, including patients with depression. The treatment can cause mood disorders, in the cases of their occurrence psychiatrist or psychologist consultations are indicated [18, 19]. Patient's family should be informed about the occurrence of these adverse events. Appropriate, according to the indications, drug usage and also proper education of the patient and his/her family determine the effective- ness of the acne drug treatment and minimization of its side effects.

\section{Aim}

The aim of this study was to evaluate the influence of acne vulgaris treatment with isotretinoin on the selected biophysical skin parameters, such as skin sebum and stratum corneum hydration levels, transepidermal water loss (TEWL) and pH value, the severity of erythema, and also hair growth parameters, such as its total count, density and the proportion of anagen hair.

\section{Material and methods}

The study included 30 patients ( 15 women and 15 men) aged 18 to 27 years (mean: $21.2 \pm 3.71$ ). They were patients at the Department of General, Esthetic Dermatology and Dermatosurgery, Medical University of Lodz. Patients were enrolled in the study based on history, physical examination and assessment of the severity of lesions. The clinical condition was assessed with the Burke and Cunliffe's scale [20], which made it possible to identify: 7 people with papulopustular, 10 with conglobata and 13 with phlegmonosa acne types. Half of the patients had previously been treated with oral antibiotics, cyproterone acetate in the case of women, and topical medications. However, the outcome was unsatisfactory.

The study group excluded pregnant women, nursing mothers and those who did not consent to the use of contraceptives. Patients with a history of psychiatric abnormalities and patients with abnormalities earlier demonstrated in laboratory tests (complete blood count picture, lipid level, total cholesterol and its fractions HDL and LDL, bilirubin, aspartate (AST) and alanine (ALT) aminotransferase, alkaline phosphatase) were not qualified to the study. Patients were informed in detail about the method of treatment and the possibility of any adverse side effects, and in the case of women, about the need for simultaneous contraception. The patients gave written consent to isotretinoin treatment. In the study group, the $0.5-1.0 \mathrm{mg} / \mathrm{kg} /$ day dosage was used. The treatment lasted from 5 to 7 months to a total overall dose of $120-150 \mathrm{mg} / \mathrm{kg}$ of body weight.

Before the treatment and after its completion, the measurements of skin biophysical and hair growth parameters were performed.

Effects of isotretinoin treatment on the skin biophysical parameters such as skin sebum content, stratum corneum hydration, TEWL value, the severity of erythema and skin pH were evaluated using the Courage-Khazaka MPA-5 device with probes: Sebumeter SM 815, Corneometer CM 825, Tewameter TM 300, Mexameter MX 18, Skin-pH-Meter PH 908.

Skin biophysical measurements were performed on the face and in the middle of the forehead. Tests were carried out in an air-conditioned room at a temperature 
of about $20-22^{\circ} \mathrm{C}$ and relative humidity of $50-60 \%$, after the resting period of about 30 min. Patients were also instructed to follow certain guidelines before testing, i.e. not to use cosmetics and not to wash the studied skin areas for about $5 \mathrm{~h}$ before the measurements. Each parameter was measured three times; the results of the mean values were taken into account in the statistical analysis.

The effect of isotretinoin treatment on hair growth parameters was assessed using videodermatoscope device (FotoFinder Dermoscope, TeachScreen) with TrichoScan Professional V 3.0.8.76 software. This non-invasive test required two patients' visits at three- day intervals. During the first visit, the hair was shaved from the right scalp parietal area of about $1.8 \mathrm{~cm}^{2}$ in all the patients. On the third day, during the second visit, their hair was dyed black. After washing off the paint with the formulation containing alcohol, images of the moistened $0.73 \mathrm{~cm}^{2}$ size scalp areas were taken at $20 \times$ magnification. Then each image was subjected to digital analysis using the TrichoScan Professional software. The following hair growth parameters were taken into consideration: total hair count, density $\left(1 / \mathrm{cm}^{2}\right)$ and anagen hair rate (\%) (Figure 1$)$.

Patients were informed that they could withdraw from the study at any time for any reason. To compare the effects of treatment before and after the therapy, the photographic documentation was performed.

The study was approved by the University Bioethics Committee (no. RNN/440/11/KB).

\section{Statistical analysis}

The statistical analysis included the arithmetic mean and median as measures of the average as well as standard deviation and coefficient of variation indicating the scale of dispersion. It also provided the minimum and maximum results. The analyzed features differed significantly from the normal distribution. To compare the results of the study before and after the treatment, the non-parametric Wilcoxon paired test was used.

\section{Results}

The results of preliminary measurements and those obtained after the treatment were different and sta- tistically significant for all skin biophysical parameters $(p<0.001)$.

The degree of skin sebum content was reduced from the value of $239.6 \pm 28.8 \mathrm{mg} / \mathrm{cm}^{2}$ to $108.5 \pm 27.9 \mathrm{mg} / \mathrm{cm}^{2}$. Before the treatment, half of the sebum results exceeded the value of 241.5, and thereafter did not exceed 109.5. A degree of the stratum corneum hydration significantly decreased; its mean was $56.9 \pm 6.84$ prior to the treat-
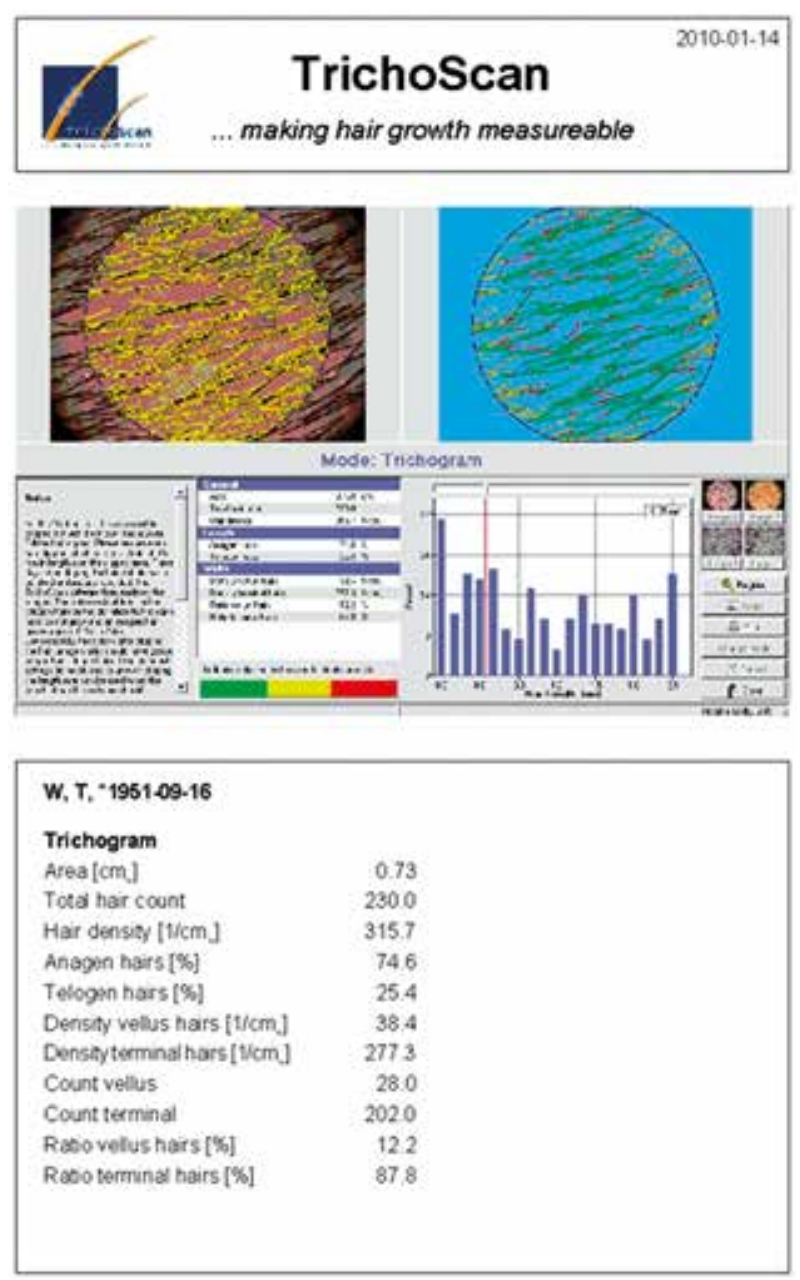

Figure 1. Results of digital TrichoScan analysis within the study scalp area

Table 1. Comparison of biophysical skin parameters in the study group $(n=30)$ before and after the treatment

\begin{tabular}{|c|c|c|c|c|c|c|c|}
\hline \multirow{2}{*}{ Biophysical skin parameters } & \multicolumn{3}{|c|}{ Before the treatment } & \multicolumn{3}{|c|}{ After the treatment } & \multirow{2}{*}{$\begin{array}{l}\text { Significance } \\
\quad p \text { value }\end{array}$} \\
\hline & Mean & Median & SD & Mean & Median & SD & \\
\hline Sebum & 239.6 & 241.5 & 28.8 & 108.5 & 109.5 & 27.9 & $<0.001$ \\
\hline Hydration & 56.9 & 57.8 & 6.84 & 43.6 & 42.8 & 8.36 & $<0.001$ \\
\hline TEWL & 12.3 & 12.4 & 3.56 & 19.8 & 19.0 & 4.88 & $<0.001$ \\
\hline Erythema & 333.2 & 341.0 & 67.2 & 416.9 & 421.5 & 71.7 & $<0.001$ \\
\hline $\mathrm{pH}$ & 5.36 & 5.31 & 0.39 & 5.96 & 5.98 & 0.28 & $<0.001$ \\
\hline
\end{tabular}




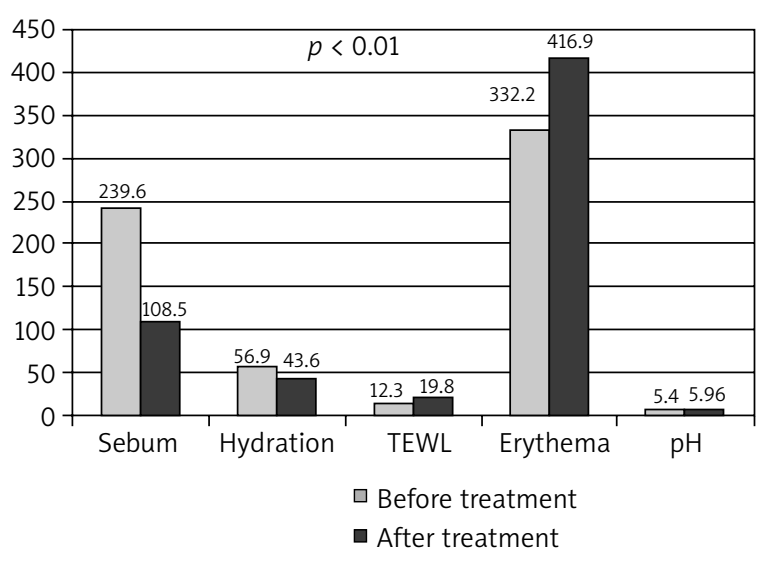

Figure 2. Comparison of biophysical skin parameters before and after the treatment $(p<0.001)$

ment and $42.8 \pm 8.36$ arbitrary units after the treatment. The TEWL value increased from the value of $12.4 \pm 3.56$ $\mathrm{g} / \mathrm{m}^{2} / \mathrm{h}$ to $19.8 \pm 4.88 \mathrm{~g} / \mathrm{m}^{2} / \mathrm{h}$. There was also a significant increase in the median value. The change in erythema intensity was statistically significant, increasing from the value of $333.2 \pm 67.2 \mathrm{U}$ to $416.9 \pm 71.7 \mathrm{U}$. The skin $\mathrm{pH}$ significantly increased from $5.36 \pm 0.39$ to $5.98 \pm 0.28$. The mean value differences for each parameter are shown in Table 1 and Figure 2.
The measurements of hair growth parameters before isotretinoin treatment showed the following results: the total hair count ranged from 141 to 379 (mean: 245.3 \pm 58 ), the median value of half of the respondents exceeded 238.8; hair density values ranged from 193.6 to 520.3 (mean: $336.6 \pm 79.5 / \mathrm{cm}$ ), in more than half of patients they were above $327.8 / \mathrm{cm}$. The anagen hair percentage value ranged from $61.2 \%$ to $86.5 \%$, and its mean value was $73 \pm 6.31 \%$. Half of the patients had the median value exceeding $74.4 \%$. The results of hair growth parameters prior to the treatment are shown in Table 2.

Hair growth parameters were also evaluated after the treatment. The total hair count ranged from 123 to 394 , its mean was $231.9 \pm 56.7$. The median in half of the respondents exceeded 233 . Hair density values ranged from 181.3 to 472.2 , the mean was $326 \pm 76.6 / \mathrm{cm}$, and in half of the studied subjects the median value exceeded $333.5 / \mathrm{cm}$. The percentage of anagen hair was from $60.3 \%$ to $83.7 \%$ (mean: $71.4 \pm 6.34$, median: $71.2 \%$ ). The results of hair growth parameters after the completion of treatment are included in Table 3.

Comparison of hair growth parameters showed statistically significant differences in the presence of all the analyzed traits. The average amount of total hair count was significantly reduced $(p<0.05)$, as well as its density $(p<0.05)$. A small but statistically significant reduction

Table 2. The results of the hair growth parameters in the study group $(n=30)$ prior to the treatment

\begin{tabular}{lccccc}
\hline \multirow{2}{*}{ Hair growth parameters } & \multicolumn{5}{c}{ Evaluated parameters } \\
\cline { 2 - 6 } & Minimum & Maximum & Mean & Median & SD \\
\hline Total number & 141.0 & 379.0 & 245.3 & 238.8 & 58.0 \\
\hline Density 1/cm & 193.6 & 520.3 & 336.6 & 327.8 & 79.5 \\
\hline Anagen hair \% & 61.2 & 86.5 & 73.0 & 74.4 & 6.31 \\
\hline
\end{tabular}

Table 3. The results of hair growth parameter measurements in the study group $(n=30)$ after the treatment

\begin{tabular}{lccccc}
\hline \multirow{2}{*}{ Hair growth parameters } & \multicolumn{5}{c}{ Evaluated parameters } \\
\cline { 2 - 6 } & Minimum & Maximum & Mean & Median & SD \\
\hline Total number & 123.0 & 394.0 & 231.9 & 233.0 & 56.7 \\
\hline Density 1/cm & 181.3 & 472.2 & 326.0 & 333.5 & 76.6 \\
\hline Anagen \% & 60.3 & 83.7 & 71.4 & 71.2 & 6.34 \\
\hline
\end{tabular}

Table 4. Comparison of hair growth parameters in the study group $(n=30)$ before and after the treatment

\begin{tabular}{|c|c|c|c|c|c|c|c|}
\hline \multirow{2}{*}{ Hair growth parameters } & \multicolumn{3}{|c|}{ Before the treatment } & \multicolumn{3}{|c|}{ After the treatment } & \multirow{2}{*}{$\begin{array}{l}\text { Significance } \\
\quad p \text { value }\end{array}$} \\
\hline & Mean & Median & SD & Minimum & Median & SD & \\
\hline Total number & 245.3 & 238.8 & 58.0 & 231.9 & 233.0 & 56.7 & $<0.05$ \\
\hline Density $1 / \mathrm{cm}$ & 336.6 & 327.8 & 79.5 & 326.0 & 333.5 & 76.6 & $<0.05$ \\
\hline Anagen \% & 73.0 & 74.4 & 6.3 & 71.4 & 71.2 & 6.3 & $<0.01$ \\
\hline
\end{tabular}


$(p<0.01)$ concerned the percentage of anagen hair. The differences between the mean values before and after the treatment in the study group are shown in Table 4 and Figure 3.

\section{Discussion}

Recently, isotretinoin has been the drug of choice in the treatment of severe types of acne vulgaris [21]. It affects the normalization of the epidermal cell differentiation processes within the hair follicle and the reduction in sebum production. It also causes reduction in $P$. acnes colonization and has anti-inflammatory effects. Numerous reports suggest good results after acne treatment with retinoids [22-24]. The outcomes of our study have confirmed the effectiveness of this medication in the treatment of acne; high improvement has been observed in most patients. The literature emphasizes the possibility of occurrence of many undesirable side effects during treatment. It has been reported that isotretinoin tolerance is highly dependent on the dosage. When the drug was used at doses higher than $0.5 \mathrm{mg} / \mathrm{kg} /$ day, the lesions of the skin and mucous membranes were noticed in almost all patients (Figures 4 and 5). Many authors have reported cheilitis of varying severity affecting $96 \%$ of patients, which, according to some authors suggests a properly chosen dose [25]. Other common side effects are as follows: skin and mucous dryness, conjunctivitis, pruritus, sensitivity to UV radiation, as well as sparse hair and hair thinning $[26,27]$. In some patients variations in the results of basic laboratory tests such as blood cell count, transaminases, bilirubin, blood lipids, cholesterol and alkaline phosphatase have been registered, which sometimes is an indication for dose reduction or the inclusion of other medicaments [28]. In our study, the patients also reported side effects, the most common were the skin dryness, its pulling and burning, and also drying

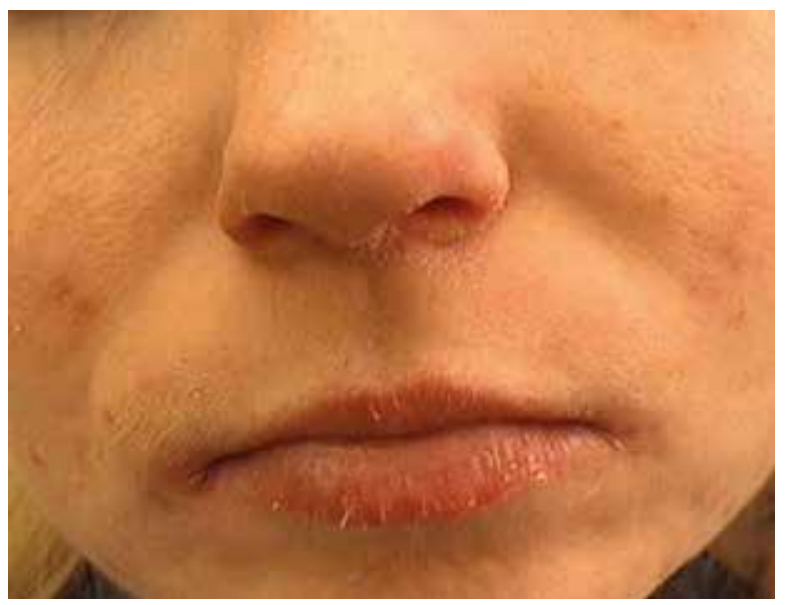

Figure 4. Skin and mucosal dryness after the treatment with isotretinoin

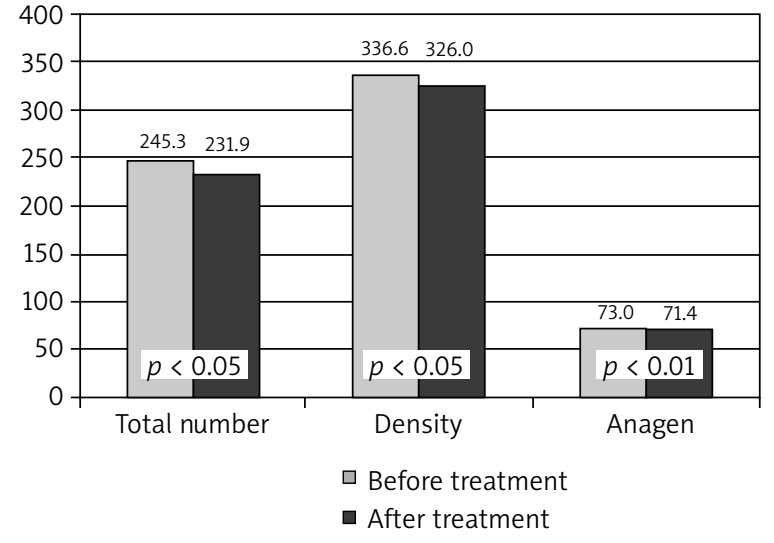

Figure 3. Comparison of hair growth parameters in the study group

of the mucous membranes. In isolated cases, myalgia, headache and bleeding from the nose were reported.

Skin dryness often observed in the treated patients and reported hair loss encouraged us to evaluate the skin barrier function as well as to carry out the examination evaluating the condition of the hair.

The epidermal barrier function was assessed using the Courage-Khazaka MPA-5 device, with probes: Sebumeter SM 815, Corneometer CM 825, Tewameter TM300, Mexameter MX 18 and Skin-pH-Meter PH 908 [29].

Isotretinoin treatment reduced the size and secretion of the sebaceous glands. The skin sebum level decrease was also demonstrated in our patients. Sebumeter measurements showed a marked reduction in the degree of the skin sebum content, which is confirmed by studies of other authors [30-32].

Our study revealed a significant reduction in the degree of stratum corneum hydration and a high increase in the TEWL values in all patients. Bergler-Czop et al. [31]

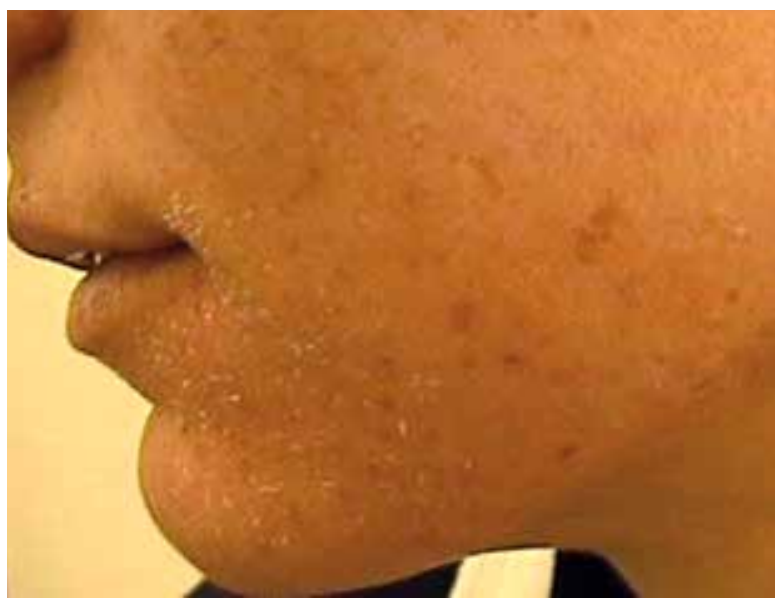

Figure 5. Dryness of the skin associated with isotretinoin therapy 
also reported a decrease in stratum corneum hydration in patients with acne treated with isotretinoin. Disruption of the epidermal barrier consisting in reducing stratum corneum hydration and increasing TEWL values are responsible for the common discomfort of the skin reported by patients.

In some patients the skin lesions of the erythema nature were observed. Mexameter study confirmed its presence, which is also quite a common symptom associated with retinoid therapy [33].

The $\mathrm{pH}$ value after oral treatment with isotretinoin increased on average by $0.6 \mathrm{U}$. Deviations from the normal 4.3-5.5 pH values affect the skin barrier function, which manifests itself in an increased susceptibility to adverse effects of external factors, such as bacterial infection and the exacerbation of the skin lesions [34]. In our patients, there was no worsening of the treatment effects, which can be explained by reduced seborrhea that has an impact on the deterioration of the $P$. acnes bacteria growth.

Due to some reports in the literature about the effect of the overall retinoid treatment on hair, the present research has been undertaken to evaluate hair growth parameters. It is emphasized in the literature that the use of high doses of retinoids can cause hair loss [35, 36]. However, this process is temporary and the hair begins to grow back after the treatment [37]. In the group of studied patients, the differences in the total hair count and hair density, as well as in the percentage of anagen hair were demonstrated. These parameters were examined using the videodermatoscope TrichoScan Professional V 3.0.8.76 software. The values were lower after the treatment and the statistical analysis of the results showed their significance at a level of $p<0.005$. There is no original work in the available literature which has reported the effects of isotretinoin on hair. Individual studies indicate that acitretin often causes hair loss [38, 39] and Seckin and Yildiz [40] reported a change in the color and structure of the hair. A decrease in the proportion of anagen hair observed in our patients can appeal for telogen effluvium hair loss.

The authors' own observations confirm the occurrence of skin and mucous membrane adverse reactions during isotretinoin treatment, which was observed in almost all patients. Their presence and poor tolerance have been emphasized by other numerous authors [22-24, 26, $28,30,35,39]$. Thus, the exact education of patients on the appropriate skin care during isotretinoin treatment seems important. It is advisable to use formulations that moisturize the skin and cleaning agents should not dry it out. It seems that implementation of other treatment regimens with lower drug doses, or shortened administration would allow to reduce the occurrence of these adverse events. Attempts were made in our clinical trials to modify the doses of isotretinoin; their results will be the subject of another report.

\section{Conclusions}

The effectiveness of the isotretinoin treatment for severe acne vulgaris types was demonstrated. The reduction in the skin sebum content during the isotretinoin treatment was found. Excessive skin dryness and mucous membrane lesions were the most commonly reported side effects. Apparent skin dryness was confirmed by biophysical skin measurements that showed an increase in TEWL values and a drop in the degree of stratum corneum hydration. The influence of the drug on an increase in the intensity of erythema and an increase in the skin $\mathrm{pH}$ were shown. Studies using the videodermatoscope device with Trichoscan software showed the effect of isotretinoin on reduction in the amount of total hair count, its density and the proportion of anagen hair, which suggests telogen effluvium hair loss.

\section{Acknowledgments}

The work financed by the own work funds (grant for young scientists) No. 502-03/7-126-01/502-54-035 and statutory work No. 503/5-064-02/503-01.

\section{References}

1. Titus S, Hodge J. Diagnosis and treatment of acne. Am Fam Physician 2012; 86: 734-40.

2. Tałasiewicz K, Ołdakowska A, Szczerkowska-Dobosz A. Evaluation of knowledge about acne vulgaris among a selected population of adolescents of Tricity schools. Postep Derm Alergol 2012; 29 6: 417-20.

3. Brzezińska-Wcisło L, Bergler-Czop B, Wcisło-Dziadecka D, Lis-Święty A. What's new in pathogenesis of acne [Polish]. Dermatol Klin 2006; 8: 275-9.

4. Silny W, Bartoszak L, Jenerowicz D, et al. Prevalence of contact allergy in children suffering from atopic dermatitis, seborrhoeic dermatitis and in healthy controls. Ann Agric Environ Med 2013; 20: 55-60.

5. Williams HC, Dellavalle RP, Garner S. Acne vulgaris. Lancet 2012; 379: 361-72.

6. Smith EV, Grindlay DJ, Williams HC. What's new in acne? An analysis of systematic reviews published in 2009-2010. Clin Exp Dermatol 2011; 36: 119-22.

7. Yazici K, Baz K, Yazici AE, et al. Disease specific quality of life is associated with anxiety and depression in patent with acne. J Eur Acad Dermatol Venerol 2004; 18: 435-9.

8. Whitney KM, Ditre CM. Management strategies for acne vulgaris. Clin Cosmet Investig Dermatol 2011; 4: 41-53.

9. Zouboulis CC. Isotretinoin revisited: pluripotent effects on human sebaceous gland cells. J Invest Dermatol 2006; 126: 2154-6.

10. Brzezińska-Wcisło L, Pierzchała E, Kamińska-Budzińska G, Bergler-Czop B, Trzmiel D. The use of retinoids in dermatology. Wiad Lek 2004; 57: 63-9.

11. Rigopoulos D, Larios G, Katsambas AD. The role of isotretinoin in acne therapy: why not as first-line therapy? Facts and controversies. Clin Dermatol 2010; 28: 24-30.

12. Zene LT, Leyden WA, Marqueling AL, Manos MM. A population-based analysis of laboratory abnormalities during isotretinoin therapy for acne vulgaris. Arch Dermatol 2006; 142: 1016-22. 
13. Akman A, Durusoy C, Senturk M, et al. Treatment of acne with intermittent and conventional isotretinoin: a randomized, controlled multicenter study. Arch Dermatol Res 2007; 299: 467-73.

14. Quereux G, Volteau C, N'Guyen JM, Dreno B. Prospective study of risk factors of relapse after treatment of acne with oral isotretinoin. Dermatology 2006; 212: 168-76.

15. Kaszuba A, Kisiel K, Uczniak S. Oral isotretinoin in the treatment of various clinical varieties of acne vulgaris [Polish]. Forum Medycyny Rodzinnej 2009; 3: 257-65.

16. Berard A, Azoulay L, Koren G, et al. Isotretinoin, pregnancies, abortions and birth defects: a population-based perspective. Br J Clin Pharm 2007; 63: 196-205.

17. Crijns HJ, Straus SM, Gispen-de Wied C, de Jong-van den Berg LT. Compliance with pregnancy prevention programmes of isotretinoin in Europe: a systematic review. Br J Dermatol 2011; 164: 238-44.

18. Chia CY, Lane W, Chibnall J, et al. Isotretinoin therapy and mood changes in adolescents with moderate to severe acne. Arch Dermatol 2005; 141: 557-60.

19. Dziemidok P, Makara-Studzińska M, Jarosz MJ. Diabetes and depression: a combination of civilization and life-style diseases is more than simple problem adding - literature review. Ann Agric Environ Med 2011; 18: 318-22.

20. Burke BM, Cunliffe WJ. The assessment of acne vulgaris the Leeds technique. Br J Dermatol 1984; 111: 83-92.

21. Simonart T. Newer approaches to the treatment of acne vulgaris. Am J Clin Dermatol 2012; 13: 357-64.

22. DiGiovanna JJ. Systemic retinoid therapy. Dermatol Clin 2001; 19: 161-7.

23. Kwiek B, Langner A. Oral isotretinoin - indications and limitations in the treatment of acne [Polish]. Postep Derm Alergol 2005; 22: 105-11.

24. Johnson BA, Nunley JR. Use of systemic agents in the treatment of acne vulgaris. Am Fam Physican 2000; 62: 1823-36.

25. Cyrulnik AA, Viola KV, Gewirtzman AJ, Cohen SR. High-dose isotretinoin in acne vulgaris: improved treatment outcomes and quality of life. Int J Dermatol 2012; 51: 1123-30.

26. Rademaker M. Adverse effects of isotretinoin: a retrospective review of 1743 patients started on isotretinoin. Australas J Dermatol 2010; 51: 248-53.

27. Osmola-Mańkowska A, Silny W, Dańczak-Pazdrowska A, et al. The sun - our friend or foe? Ann Agric Environ Med 2012; 19: 805-9.

28. Tripathi SV, Gustafson CJ, Huang KE, Feldman SR. Side effects of common acne treatments. Expert Opin Drug Saf 2013; 12: 39-51.

29. Polańska A, Dańczak-Pazdrowska A, Silny W, et al. Evaluation of selected skin barrier functions in atopic dermatitis in relation to the disease severity and pruritus. Postep Derm Alergol 2012; 29: 373-7.

30. Ellis CN, Krach KJ. Uses and complications of isotretinoin therapy. J Am Acad Dermatol 2001; 45: 150-7.

31. Bergler-Czop B, Brzezińska-Wcisło L. Assessment of the skin parameters moisture, melanin content, $\mathrm{pH}$ and production of sebum in patients treated with oral isotretinoine - preliminary report [Polish]. Postep Derm Alergol 2010; 27: 83-9.

32. Janiczek-Dolphin N, Cook J, Thiboutot D, et al. Can sebum reduction predict acne outcome? Br J Dermatol 2010; 163: 683-8.

33. Schurer NY, Bock M. Lowering lesional surface pH in acne: a new treatment sodality for Herpfix. J Dermatolog Tret 2009; 20: 27-31.
34. Zouboulis CC. The truth behind this undeniable efficacy-recurrence rates and relapse risk factors of acne treatment with oral isotretinoin. Dermatology 2006; 212: 168-76.

35. Bergler-Czop B, Brzezińska-Wcisto L. The new therapy schema of the various kinds of acne based on the mucosa-skin side effects of the retinoids. Cutan Ocul Toxicol 2012; 31: 188-94.

36. Pastuszka M, Kaszuba A. Acitretin, a systemic retinoid for the treatment of psoriasis - current state of knowledge. Postep Derm Alergol 2011; 28: 285-92.

37. Żaba R. Safety of the treatment with retinoids [Polish]. Postep Derm Alergol 2006; 23: 161-74.

38. Dréno B, Thiboutot D, Gollnick H, et al. Global alliance to improve outcomes in acne. Large-scale worldwide observational study of adherence with acne therapy. Int I Dermatol 2010; 49: 448-56.

39. David M, Hodak E, Lowe N. Adverse effects of retinoids. Med Toxicol 1988; 119: 609-14.

40. Seckin D, Yildiz A. Repigmentation and curling of hair after acitretin therapy. Australas J Dermatol 2009; 50: 214-6. 